\title{
DENTAL ARCH AND SMILE CHANGES FOLLOWING MINISCREW ANCHORED EN-MASSE RETRACTION OF ANTERIOR TEETH IN CLASS II DIVISION 1 MALOCCLUSION
}

\author{
Shaimaa Elmarhoumy* and Osama Eissa*
}

\begin{abstract}
Objective: To evaluate dental arch and smile changes after miniscrew anchored en-masse retraction of maxillary anterior teeth in Class II division 1 malocclusion cases.

Methods: A total of 22 adult patients (mean age, $19.78+1.24$ years) with Class II division 1 malocclusion were randomly assigned to 2 groups; group I (11 patients treated with miniscrew anchored en-masse retraction) and group II (11 patients treated with two-step retraction using conventional anchorage). Skeletal, dentoalveolar and smile changes were analyzed in both groups using standardized photographs, study casts, and lateral cephalograms before and after space closure.

Results: Miniscrew anchored en-masse retraction showed a statistically significant decrease in upper incisor display (U1UL) $(-2.22 \pm 1.33 ; \mathrm{P}<0.05)$. There was a significant increase in nasolabial angle $(-13.6 \pm 8.09, P \leq 0.001 ; 6.6 \pm 5.93, P=0.007)$ for group I and II, respectively. Non-significant difference was found in buccal corridor and smile arc measurements in both groups $(\mathrm{P}>0.05)$. Group II demonstrated a statistically significant decrease in IMW $(-1.63 \pm 1.19, \mathrm{P}<0.05)$ and significant mesialization of maxillary first molars (U6-MR, U6-LR) $(-2.46+1.64,-1.03+1.13, \mathrm{P}<0.05)$.

Conclusion: The use of miniscrews as a means of anchorage during retraction of maxillary anterior teeth provides an absolute anchorage for maxillary first molars with in either anteroposterior or vertical direction. Therefore, miniscrew position could effectively reduce upper incisors display without altering buccal corridor dimensions or affecting the smile arc.
\end{abstract}

KEYWORDS: Dental arch, Smile, Buccal corridor, miniscrew, en-masse retraction

\section{INTRODUCTION}

Improvement of dentofacial esthetic has been the most important treatment objectives of modern orthodontics and the main motivation for the patients to seek orthodontic treatment ${ }^{[1]}$. Malocclusion leads to poor esthetic appearance which could negatively affect psychosocial wellbeing of the patients ${ }^{[2]}$. It has been claimed the facial features have a potential influence on self-perceived appearance particularly

\footnotetext{
* Lecturer of Orthodontics, Faculty of Dentistry, Tanta University, Egypt.
} 
in adolescents where self-perceived impact of dental esthetics is influenced by severity of malocclusion and oral health-related quality of life ${ }^{[3]}$.

Extraction procedures can be carried out for dental camouflaging of Class II malocclusion, whereas surgical correction can be performed in cases that cannot be improved via orthodontic therapy ${ }^{[4]}$. One of the major treatment goals in Class II division 1 malocclusion is to reduce the proclination of maxillary incisors. Therefore, extraction of maxillary first premolars has been developed as a treatment strategy to provide space for anterior retraction and to decrease facial convexity and soft tissue procumbency particularly in cases with increased overjet and minimal or no crowding in the lower arch ${ }^{[5]}$. Anchorage control in maxillary premolar extraction is the cornerstone of the treatment success. Conventional methods of anchorage reinforcement include increasing number of teeth in the anchor unit, transpalatal arch (TPA), Nance holding appliance, headgears and interarch elastics ${ }^{[6]}$. Use of miniscrew for reinforcement of orthodontic anchorage has become increasingly common in recent years, particularly for the space closure in maximum anchorage requirements as well as Class II malocclusion ${ }^{[7,8]}$.

It has been previously suggested that premolar extraction treatment would result in narrowing of dental arches which, in turn, is associated with a less esthetic smile because of a decreased fullness of the dentition during a smile and unaesthetic negative spaces lateral to the buccal segments ${ }^{[9,10]}$. On the contrary, several other studies have indicated that constricted arch widths are not a usual outcome of extraction treatment which subsequently has a no significant effect on smile esthetics ${ }^{[11,12]}$. Therefore, a more comprehensive clinical trial was needed to assess dental arch and smile changes following space closure using miniscrews anchored enmasse retraction of maxillary anterior teeth versus conventional anchorage methods.

\section{Specific Objective or Hypothesis}

The aim of the present study was to evaluate dental arch and smile changes following premolar extraction and space closure using miniscrew anchored en-masse retraction of maxillary anterior teeth anchorage versus conventionally anchored two-step retraction. The null hypothesis was that there would be no difference in dental arch and smile changes between miniscrew and conventional anchorage in space closure.

\section{MATERIALS AND METHODS}

\section{Trial Design and any Changes after Trial Com- mencement}

This study was a single center randomized clinical trial. No changes occurred during the trial.

\section{Participants, Eligibility Criteria, and Settings}

The study design was approved by the Research Ethics Committee of Faculty of Orthodontics of Dentistry, Tanta University, Egypt.

The patients were included according to following criteria:

1. Angle Class II division 1 malocclusion.

2. An orthodontic treatment plan required extraction of two maxillary first premolars and maximum anchorage (with or without extraction in the lower arch)

3. A minimum age of 18 years at the start of the treatment.

4. No medical or dental contraindications for orthodontic treatment.

5. No extracted or missing permanent teeth (third molars are excluded)

Written informed consents were obtained from the patients explaining the treatment procedures in detail for all participants. 


\section{Sample Size Calculation}

Sample size calculation was based on the ability to detect a clinically meaningful difference in arch length of $2 \mathrm{~mm}( \pm 1.5 \mathrm{~mm})$, with an alpha error of 0.05 and a test power of $80 \%$. The calculation was carried out using software $G^{*}$ Power (Universität Düsseldorf, Germany). The sample size was 9 patients in each group. To compensate for possible $20 \%$ dropouts during the study period, 11 patients were included in each group.

\section{Randomization}

Patients with class II division 1 having the previously mentioned inclusion criteria were randomly selected from orthodontic patients coming to Orthodontic clinic, Faculty of Dentistry, Tanta University, using a computer-generated random list.

The patients were randomly allocated into two groups using sequentially numbered, opaque, sealed envelopes.

Group 1: Consisted of 11 patients ( 3 males and 8 females) treated with miniscrew anchorage for enmasse retraction of the six maxillary anterior teeth.

Group 2: Consisted of 11 patients (4 male and 7 females) treated with conventional method of anchorage reinforcement for two step retraction of the maxillary canine and incisors.

\section{Interventions}

Group 1 (Miniscrew group): The 0.022-inch slot Roth brackets (Ormco Corporation, Orange, CA) were bonded to both arches. After initial leveling and aligning, 0.019 X 0.025 -in SS archwire with crimpable hooks placed distal to the maxillary lateral incisors and left in place for at least four weeks before starting retraction. Miniscrews (1.3 X $8 \mathrm{~mm}$; Absoanchor Microimplant, Dentos, Daegu, Korea) were placed bilaterally between maxillary second premolar and first permanent molar at the level of mucogingival junction. A force of $150-\mathrm{g}$ was applied immediately ${ }^{[13,14]}$. on each side with $\mathrm{NiTi}$ closed coil spring extending from the miniscrew to the crimpable hook. (Figure 1). All patients were recalled every four weeks for intraoral reactivation. Excess wire was clipped distal to the molar buccal tubes, and the Ni-Ti springs were checked to confirm 150 -g activation. Measurements of the stability of the implant, soft-tissue health around the implant, and patient comfort were recorded at every clinical appointment.

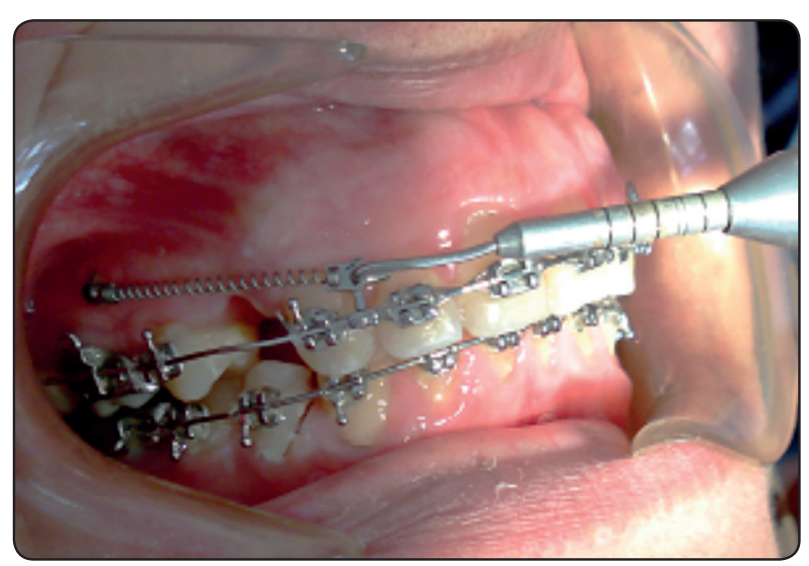

Fig. (1): NiTi coil spring for en-masse retraction of maxillary anterior teeth

Group 2 (Conventional anchorage group): Conventional anchorage was established using TPA, banding of the maxillary second molar, maxillary posterior teeth were figure eight ligated with SS ligature wire. Anterior teeth were retracted sequentially; A force of $100-\mathrm{g}$ was applied to retract maxillary canine by $\mathrm{Ni}-\mathrm{Ti}$ closed coil spring ligated with a wire to the canine bracket hook ${ }^{[15]}$. After canine retraction, the maxillary incisors were retracted by $130-\mathrm{g}$ force using $\mathrm{Ni}-\mathrm{Ti}$ closed coil spring extending from the hook of the buccal tube on the first molar band to helices placed distal to lateral incisors ${ }^{[16]}$ (Figure 2).

\section{Outcomes}

The main outcome of the study was the dental arch and smile changes following extraction of maxillary first premolars using two different 

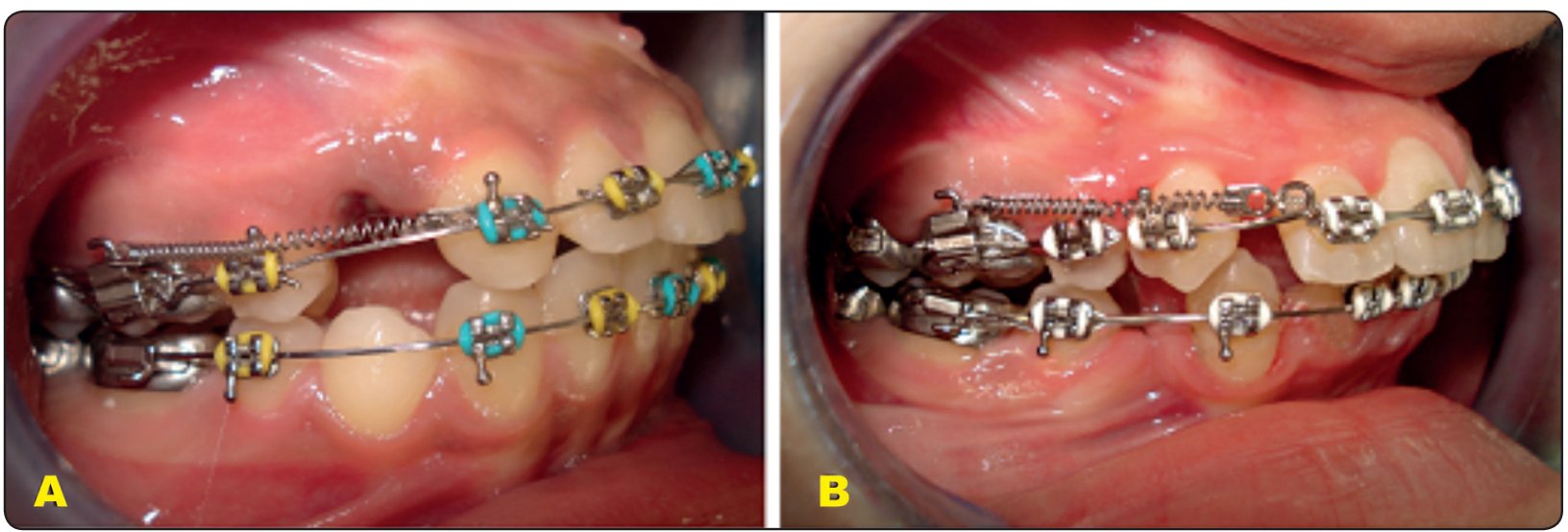

Fig. (2): (A) Retraction of maxillary canines by Ni-Ti closed coil spring. (B) Retraction of maxillary incisors

anchorage methods. The secondary outcomes were the skeletal and dentoalveolar treatment effects.

\section{Cephalometric Analysis}

Lateral cephalometric radiographs were taken by a single technician on the same radiographic machine immediately before (T1) and after space closure (T2) to compare treatment outcomes (Figure 3). All landmarks were digitized, and measurements were recorded using Dolphin Imaging software version 11.8 (Dolphin Imaging, Chatsworth, Calif).

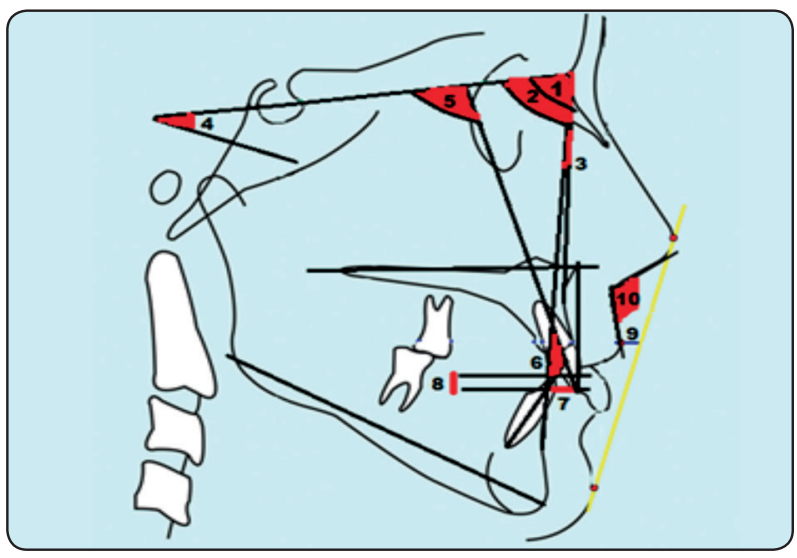

Fig 3: Cephalometric measurements: (1) SNA (2) SNB (3) ANB (4) SN-MP (5) U1-SN (6) U1-PP (7) U6-PP (8) Overjet (9) Overbite (10) U1-L1 (11) UL-E line (12) Nasolabial angle

\section{Model Analysis}

Study casts were taken immediately before (T1) and after space closure (T2). All dental casts were digitized by a 3-dimensional model laser scanner (Zirkon Scanner S600 ARTI, ITALY). All measurements were done using materialize 3-matic software version 13. (Table1, Figure 4).

TABLE (1): Dental cast measurements.

\begin{tabular}{|l|l|}
\hline 1. ICW & $\begin{array}{l}\text { Distance between cusp tips of right and left } \\
\text { canine. }\end{array}$ \\
\hline 2. IPMW & $\begin{array}{l}\text { Distance between cusp tips of right and left } \\
\text { second premolar. }\end{array}$ \\
\hline 3. IMW & $\begin{array}{l}\text { Distance between cusp tips of mesiobuccal } \\
\text { cusps of right and left first molars. }\end{array}$ \\
\hline $\begin{array}{l}\text { 4. Molar } \\
\text { Rotation }\end{array}$ & $\begin{array}{l}\text { Angle between midpalatal raphe and a line } \\
\text { running through the mesiobuccal and disto- } \\
\text { buccal cusps of the first molars (right \& left) }\end{array}$ \\
\hline 5. U6- & $\begin{array}{l}\text { Distance between the mesial contact points } \\
\text { of first molars and the medial end of the third } \\
\text { primary rugae (right \& left). }\end{array}$ \\
\hline 6. U6-LR & $\begin{array}{l}\text { Distance between the mesial contact points } \\
\text { of first molars and the lateral end of the third } \\
\text { primary rugae (right \& left). }\end{array}$ \\
\hline
\end{tabular}




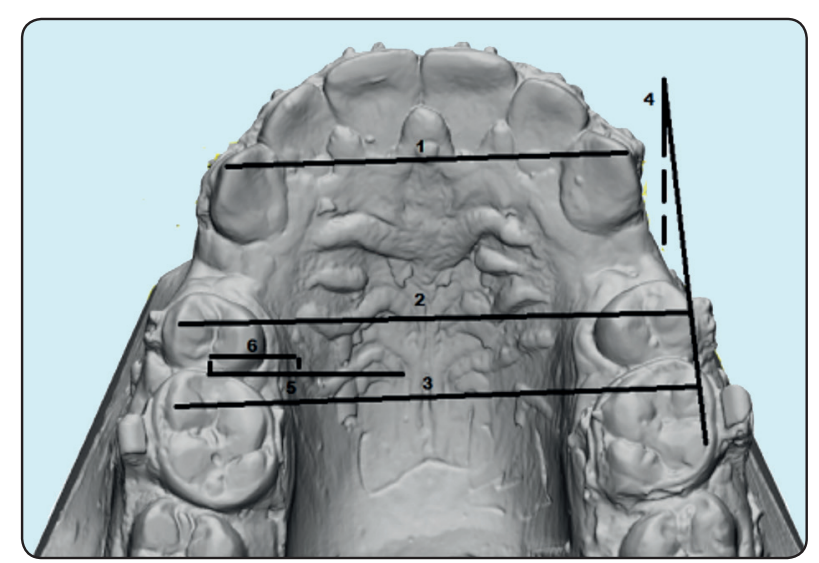

Fig. (4): Dental cast measurements: (1) ICW (2) IPM (3) IMW (4) Molar rotation (5) U6-MR (6) U6-LR

\section{Smile analysis}

All photographs were obtained with by the same clinician using the same camera (Canon EOS 600D; Canon, Tokyo, Japan) with 1:1 magnification at an object-to-lens distance of 30 inches in JPEG file format. For each participant, variables like include lip length, smile arc, upper incisors display in rest and smile position were collected and analyzed (Figure 5 \& 6).

Patients were informed to look through a point at their eye level during image capture to ensure natural head posture. The photos were cropped to display only the immediate perioral area.
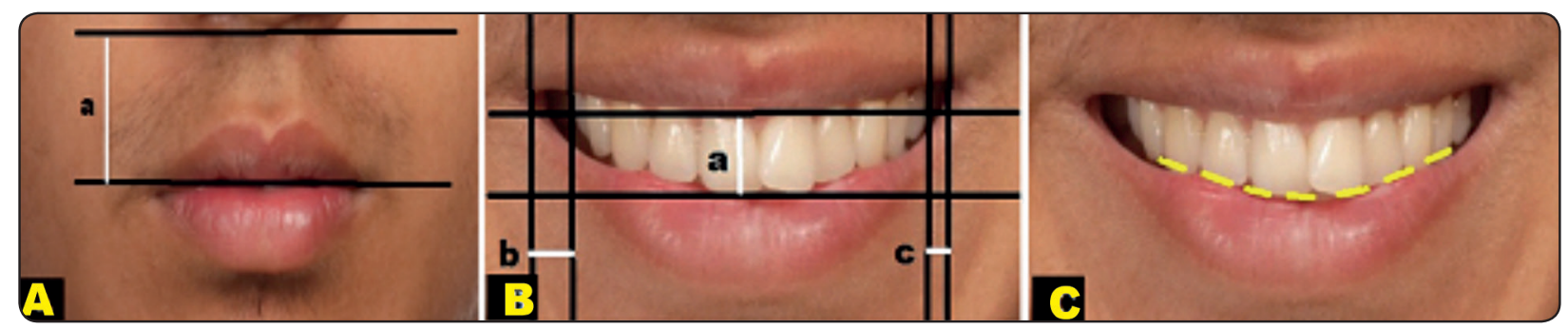

Fig. (5): Smile measurements: (A) upper lip length (B) Smile photograph:(a) upper lip to upper incisor edge (b) Rt buccal corridor space (c) Lt buccal corridor (C) Smile arc
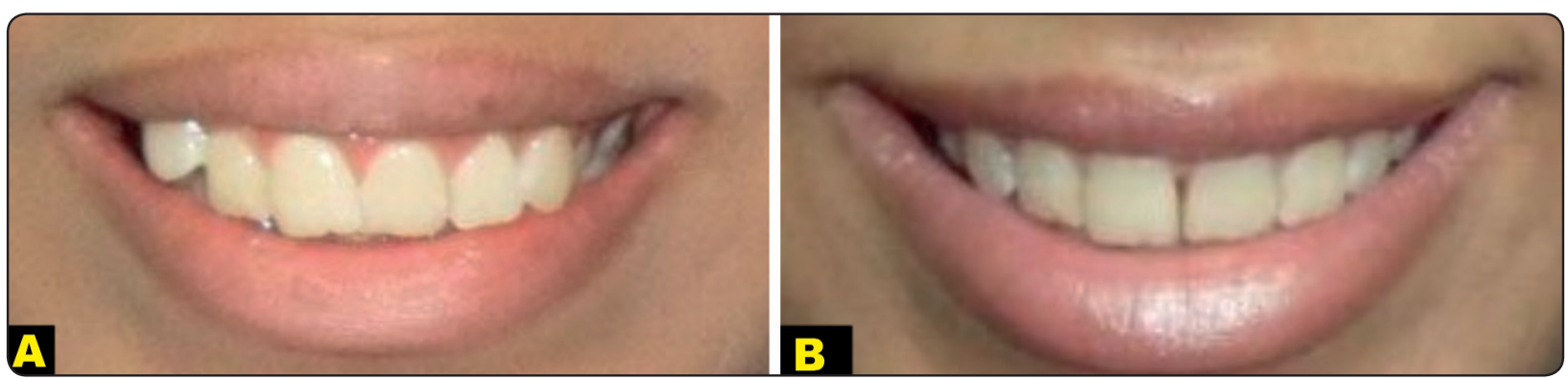

Fig. (6): (A) pre-treatment smile photograph (B) post-treatment smile photograph of the same patient

\section{Reliability}

Measurements were repeated 2 weeks after the initial measurements on 10 randomly selected patients, 5 from each group. The reliability of these repeated measurements was tested using the intraclass correlation coefficient (ICC) with a 95\% confidence interval. ICC values ranged from 0.91 to 0.96 , which indicated a high degree of reliability.

\section{Blinding}

Blinding of both patient and operator to the intervention was impossible. However, the investigator who analyzed the photographs and lateral cephalometric radiographs was blinded regarding the origin of the cast and the group to which the individual subjects belonged. All data were labelled with numbers and sent to statistician who was also blinded regarding patients' groups. 


\section{Statistical Analysis}

Statistical analysis was performed with SPSS Version 21.0 (SPSS Inc, Chicago, III). Shapiro-Wilk test showed that the data were normally distributed $(P>0.05)$. For normally distributed data, parametric tests were used. Paired t-test was performed to detect changes within each group. Independent t-test was used for comparing the mean changes between the treatment groups. The chi-square test was used to evaluate statistically significant differences in the frequencies of smile arc between groups.

\section{RESULTS}

\section{Participants Flow and Patient Attrition}

A CONSORT diagram in Figure 7 shows all patients recruited in the study. One patient was excluded from group I due to repeated bracket failure and missing appointments. Other patient was excluded from group II because he refused to continue the trial.

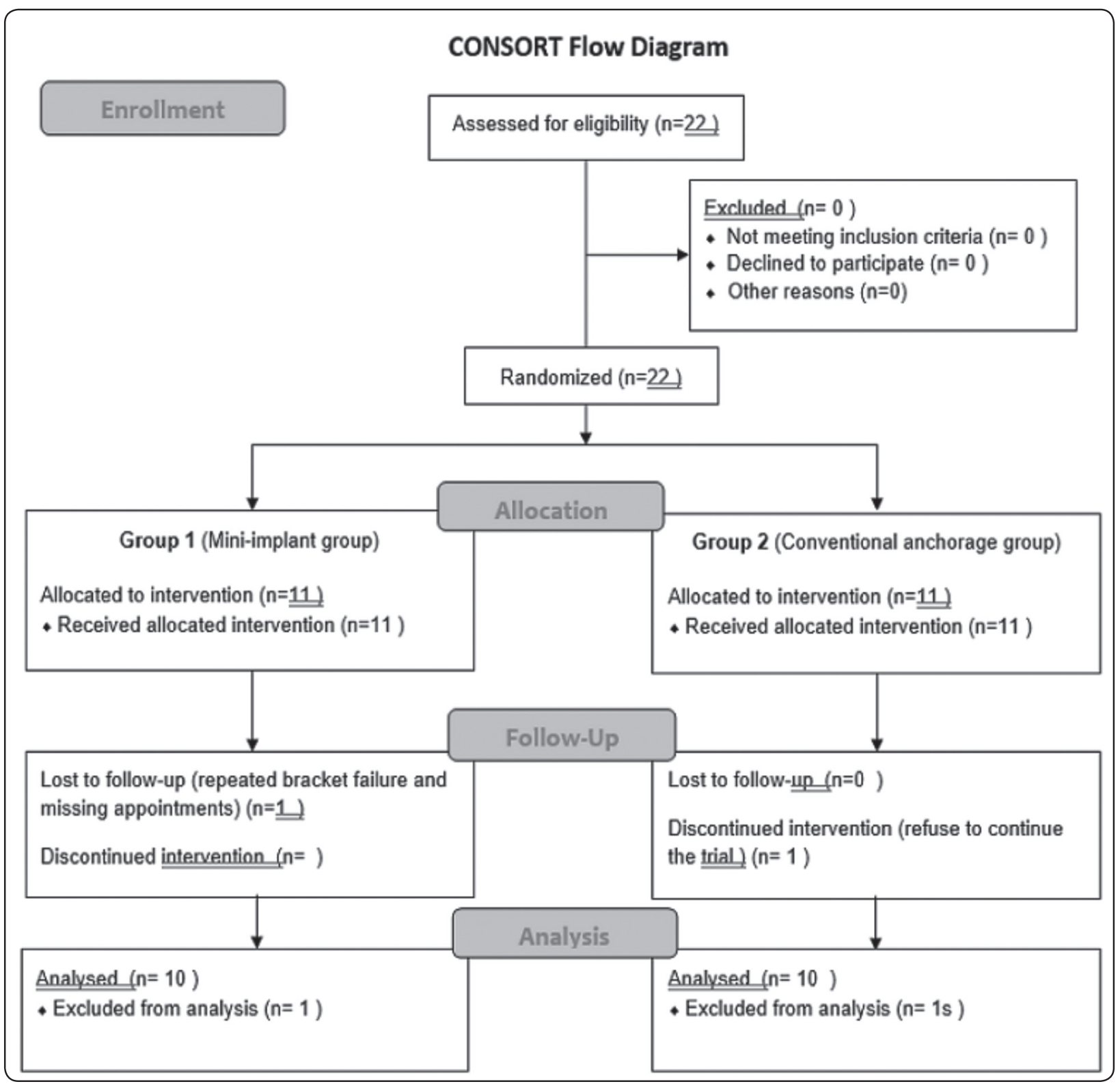

Fig 7: A CONSORT diagram shows all patients recruited in the study. 


\section{Baseline Data}

Groups were well matched regarding patients ages and treatment duration as there were no significant differences between both groups $(P>0.05)$ (Table 2$)$. There were no statistically significant differences between both groups at $\mathrm{T} 1$ for all analyzed measurements except for SN-MP, U1-PP and NLA (Table 3). Comparisons of skeletal, dental, and soft tissue changes between $\mathrm{T} 1$ and $\mathrm{T} 2$ for both groups are shown in Table 4. Comparisons between both groups are presented in Table 5. Smile arc changes are shown in Table 6.

TABLE (2): Comparison of the mean age and treatment duration among both study groups.

\begin{tabular}{|c|c|c|c|c|c|}
\hline Variables & \multicolumn{2}{|c|}{$\begin{array}{c}\text { Group 1 } \\
\text { (Mini-implant } \\
\text { Anchorage) }\end{array}$} & \multicolumn{2}{c|}{$\begin{array}{c}\text { Group 2 } \\
\text { (Conventional } \\
\text { Anchorage) }\end{array}$} & P \\
\hline & Mean & SD & Mean & SD & \\
\hline Age (years) & 19.78 & 1.24 & 18.98 & 1.16 & 0.15 \\
\hline Duration (months) & 9.69 & 2.63 & 12.41 & 2.78 & 0.52 \\
\hline
\end{tabular}

$P>0.05$ (Non-significant)

TABLE (3) The pre-treatment mean values of all parameters in each group and significance values of the differences between both groups

\begin{tabular}{|c|c|c|c|c|c|}
\hline & \multicolumn{2}{|c|}{ Group 1} & \multicolumn{2}{|c|}{ Group 2} & \multirow{3}{*}{$P$} \\
\hline & \multicolumn{2}{|c|}{ Mini-implant Anchorage } & \multicolumn{2}{|c|}{ Conventional Anchorage } & \\
\hline & Mean & SD & Mean & SD & \\
\hline SNA & 83.900 & 1.9120 & 83.000 & 3.6510 & 0.341 \\
\hline SNB & 75.800 & 2.3940 & 76.800 & 3.3270 & 0.293 \\
\hline ANB & 8.100 & 3.0710 & 6.200 & 2.7410 & 0.051 \\
\hline SN-MP & 37.200 & 4.9620 & 33.600 & 4.8810 & $0.032 *$ \\
\hline U1-SN & 110.900 & 6.8710 & 114.100 & 4.0400 & 0.068 \\
\hline U1-PP & 31.600 & 6.0260 & 24.400 & 3.3730 & $0.029 *$ \\
\hline U6-PP & 25.900 & 2.685 & 24.650 & 2.334 & 0.067 \\
\hline Overjet & 6.330 & .9730 & 6.870 & 1.1908 & .281 \\
\hline Overbite & 5.100 & 1.4445 & 4.540 & 1.0752 & .338 \\
\hline U1-L1 & 120.500 & 11.4330 & 116.200 & 7.6270 & 0.080 \\
\hline UL-Eline & .310 & 2.9558 & .640 & 2.2853 & .783 \\
\hline NLA & 99.900 & 5.5470 & 91.400 & 7.7340 & $0.001 *$ \\
\hline U lip length & 21.170 & 2.7637 & 20.710 & 2.6971 & .711 \\
\hline BCRT & 3.3200 & .89914 & 2.9800 & 1.07373 & .453 \\
\hline BCLT & 3.1100 & .90609 & 2.4200 & 1.11833 & .148 \\
\hline U1-UL & 9.0500 & 1.97217 & 8.7800 & 1.50318 & .735 \\
\hline UL-Eline & .310 & 2.9558 & .640 & 2.2853 & .783 \\
\hline ICW & 34.910 & 1.699 & 36.870 & 2.480 & 0.054 \\
\hline IPMW & 45.970 & 1.697 & 46.700 & 1.081 & 0.266 \\
\hline IM & 49.460 & 2.854 & 51.620 & 1.876 & 0.061 \\
\hline MR(RT) & 13.690 & 2.791 & 13.520 & 3.761 & 0.910 \\
\hline MR(LT) & 14.090 & 4.366 & 13.390 & 3.059 & 0.683 \\
\hline (RT)U6-MR & 25.090 & 2.059 & 25.770 & 1.397 & 0.399 \\
\hline (RT)U6-LR & 15.270 & 3.726 & 15.570 & 2.700 & 0.839 \\
\hline (LT) U6-MR & 25.340 & 2.084 & 25.340 & 0.866 & 1.000 \\
\hline (LT) U6-LR & 16.620 & 3.740 & 15.270 & 2.773 & 0.371 \\
\hline
\end{tabular}


TABLE (4): Skeletal, dental and smile changes in both groups.

\begin{tabular}{|c|c|c|c|c|c|c|c|c|c|c|}
\hline \multirow{3}{*}{ Variable } & \multicolumn{5}{|c|}{ Group 1 ( Mini-implant Anchorage ) } & \multicolumn{5}{|c|}{ Group 2 ( Conventional Anchorage ) } \\
\hline & \multicolumn{2}{|c|}{ Pre- treatment $(\mathrm{T} 1)$} & \multicolumn{2}{|c|}{ Post-treatment (T2) } & \multirow{2}{*}{$P$} & \multicolumn{2}{|c|}{$\begin{array}{l}\text { Pre- treatment } \\
\text { (T1) }\end{array}$} & \multicolumn{2}{|c|}{ Post-treatment (T2) } & \multirow{2}{*}{$P$} \\
\hline & Mean & SD & Mean & SD & & Mean & SD & Mean & SD & \\
\hline SNA & 83.900 & 1.9120 & 82.600 & 1.5060 & $<0.001 *$ & 83.000 & 3.6510 & 81.000 & 2.3570 & $0.03^{*}$ \\
\hline SNB & 75.800 & 2.3940 & 76.700 & 1.9470 & 0.019 & 76.800 & 3.3270 & 76.100 & 2.6440 & 0.132 \\
\hline ANB & 8.100 & 3.0710 & 5.900 & 2.5580 & $<0.001 *$ & 6.200 & 2.7410 & 4.900 & 1.9690 & 0.180 \\
\hline SN-MP & 37.200 & 4.9620 & 35.300 & 4.8090 & $<0.001 *$ & 33.600 & 4.8810 & 34.200 & 4.5900 & 0.081 \\
\hline U1-SN & 110.900 & 6.8710 & 99.300 & 9.0810 & $0.004 *$ & 114.100 & 4.0400 & 96.600 & 5.8350 & $<0.001 *$ \\
\hline U1-PP & 31.600 & 6.0260 & 29.300 & 2.7910 & $<0.001 *$ & 24.400 & 3.3730 & 30.500 & 4.2490 & $<0.001 *$ \\
\hline U6-PP & 25.900 & 2.685 & 25.100 & 2.685 & $0.022 *$ & 24.650 & 2.334 & 25.600 & 2.319 & $<0.001 * *$ \\
\hline Overjet & 6.330 & .9730 & 2.120 & 1.0768 & .000 & 6.870 & 1.1908 & 2.310 & .6471 & .000 \\
\hline Overbite & 5.100 & 1.4445 & 3.700 & 1.0914 & .014 & 4.540 & 1.0752 & 6.350 & 1.9733 & .005 \\
\hline U1-L1 & 120.500 & 11.4330 & 138.000 & 9.0310 & $<0.001 *$ & 116.200 & 7.6270 & 138.500 & 9.4780 & $<0.001 *$ \\
\hline UL-Eline & .310 & 2.9558 & -.640 & 3.0321 & .074 & .640 & 2.2853 & -.530 & 1.6378 & .022 \\
\hline NLA & 99.900 & 5.5470 & 113.500 & 6.1330 & $0.001 *$ & 91.400 & 7.7340 & 98.000 & 4.3460 & $0.007 *$ \\
\hline U lip length & 21.170 & 2.7637 & 21.450 & 3.0351 & .465 & 20.710 & 2.6971 & 20.750 & 1.7024 & .941 \\
\hline BCRT & 3.3200 & .89914 & 2.8100 & 1.26179 & .090 & 2.9800 & 1.07373 & 2.8100 & 1.05351 & .610 \\
\hline BCLT & 3.1100 & .90609 & 2.3200 & 1.17549 & .059 & 2.4200 & 1.11833 & 2.2400 & 1.06896 & .550 \\
\hline U1-UL & 9.0500 & 1.97217 & 6.8300 & 2.26865 & .001 & 8.7800 & 1.50318 & 9.4400 & 1.76774 & .138 \\
\hline ICW & 34.910 & 1.6993 & 34.820 & 1.8837 & 0.820 & 36.870 & 2.4802 & 34.940 & 1.4462 & 0.053 \\
\hline IPMW & 45.970 & 1.6971 & 43.130 & 1.9850 & $0.001 *$ & 46.700 & 1.0812 & 43.280 & 1.7675 & $0.000 * *$ \\
\hline IM & 48.830 & 2.8539 & 49.460 & 2.1448 & 0.494 & 51.620 & 1.8760 & 49.990 & 1.9706 & $0.002^{*}$ \\
\hline MR(RT) & 13.690 & 2.7906 & 9.440 & 2.3968 & $0.006^{*}$ & 13.520 & 3.7614 & 14.800 & 4.3292 & 0.132 \\
\hline $\operatorname{MR}(\mathbf{L T})$ & 14.090 & 4.3656 & 10.490 & 3.0450 & $0.006^{*}$ & 13.390 & 3.0592 & 16.460 & 3.2569 & $0.001 *$ \\
\hline (RT) U6-MR & 25.090 & 2.0594 & 23.930 & 1.6378 & 0.073 & 25.770 & 1.3969 & 23.310 & 1.8303 & $0.001 *$ \\
\hline (RT) U6-LR & 15.270 & 3.7256 & 14.690 & 3.2525 & 0.403 & 15.570 & 2.7002 & 14.540 & 2.3595 & $0.018 *$ \\
\hline (LT) U6-MR & 25.340 & 2.0844 & 24.760 & 2.3500 & 0.313 & 25.340 & 0.8656 & 23.520 & 1.1448 & $0.000 * *$ \\
\hline (LT) U6-LR & 16.620 & 3.7398 & 15.960 & 3.9705 & 0.308 & 15.270 & 2.7733 & 13.340 & 2.5391 & $0.002 *$ \\
\hline
\end{tabular}

$P>0.05$ (Non significant)

$* P \leq 0.05$ (Significant)

$* * P \leq 0.001$ (Highly significant) 
TABLE (5): Comparison of the treatment effects between both groups.

\begin{tabular}{|c|c|c|c|c|c|}
\hline \multirow{2}{*}{ Variable } & \multicolumn{2}{|c|}{ Group 1 ( Mini-implant Anchorage ) } & \multicolumn{2}{|c|}{ Group 2 ( Conventional Anchorage ) } & \multirow{2}{*}{$P$} \\
\hline & Mean & SD & Mean & SD & \\
\hline SNA $^{\mathbf{0}}$ & -1.30 & 0.68 & -2 & 2.45 & 0.395 \\
\hline SNB $^{\circ}$ & 0.90 & 0.99 & -0.7 & 1.34 & $0.007^{*}$ \\
\hline $\mathrm{ANB}^{\circ}$ & -2.20 & 1.23 & -1.3 & 2.83 & 0.369 \\
\hline SN-MP ${ }^{0}$ & -1.90 & 0.74 & 0.6 & 0.97 & $<0.001 * *$ \\
\hline U1-SN ${ }^{0}$ & -11.60 & 7.66 & -17.5 & 5.04 & 0.057 \\
\hline U1-PP & -2.30 & 1.06 & 1.1 & 1.19 & $<0.001 * *$ \\
\hline U6-PP & -0.800 & 0.919 & 0.950 & 0.497 & $<0.001 * *$ \\
\hline Overjet & -4.21 & 1.56 & -4.56 & 1.31 & .593 \\
\hline Overbite & -1.40 & 1.45 & 1.81 & 1.55 & .000 \\
\hline U1UL & -2.57 & 0.98 & 0.57 & 1.51 & $<0.001 * *$ \\
\hline UL-Eline & -0.95 & 1.48 & -1.17 & 1.34 & .732 \\
\hline NLA & 13.60 & 8.09 & 6.60 & 5.93 & $0.04 *$ \\
\hline U lip length & 0.28 & 1.16 & 0.04 & 1.67 & .713 \\
\hline BCRT & -0.51 & 0.847 & -0.17 & 1.02 & 0.428 \\
\hline BCLT & -0.79 & 1.158 & -0.18 & 0.92 & 0.208 \\
\hline ICW & -0.0900 & 1.2142 & -1.9300 & 2.7390 & 0.068 \\
\hline IPMW & -2.8400 & 1.8081 & -3.4200 & 1.6572 & 0.464 \\
\hline IM & 0.6300 & 2.7976 & -1.6300 & 1.1908 & 0.312 \\
\hline MR(RT) & -4.2500 & 3.7963 & 1.2800 & 2.4462 & $0.001 *$ \\
\hline $\operatorname{MR}(\mathbf{L T})$ & -3.6000 & 3.1857 & 3.0700 & 2.0833 & $0.000 * *$ \\
\hline (RT) U6-MR & -1.1600 & 1.8106 & -2.4600 & 1.6386 & 0.110 \\
\hline (RT) U6-LR & -0.5800 & 2.0885 & -1.0300 & 1.1314 & 0.557 \\
\hline (LT) U6-MR & -0.5800 & 1.7178 & -1.8200 & 0.8879 & 0.058 \\
\hline (LT) U6-LR & -0.6600 & 1.9306 & -1.9300 & 1.4476 & 0.113 \\
\hline
\end{tabular}

$P>0.05$ (Non-significant)

$* P \leq 0.05$ (Significant)

$* * P \leq 0.001$ (Highly significant) 
TABLE (6): Smile Arc changes in both groups.

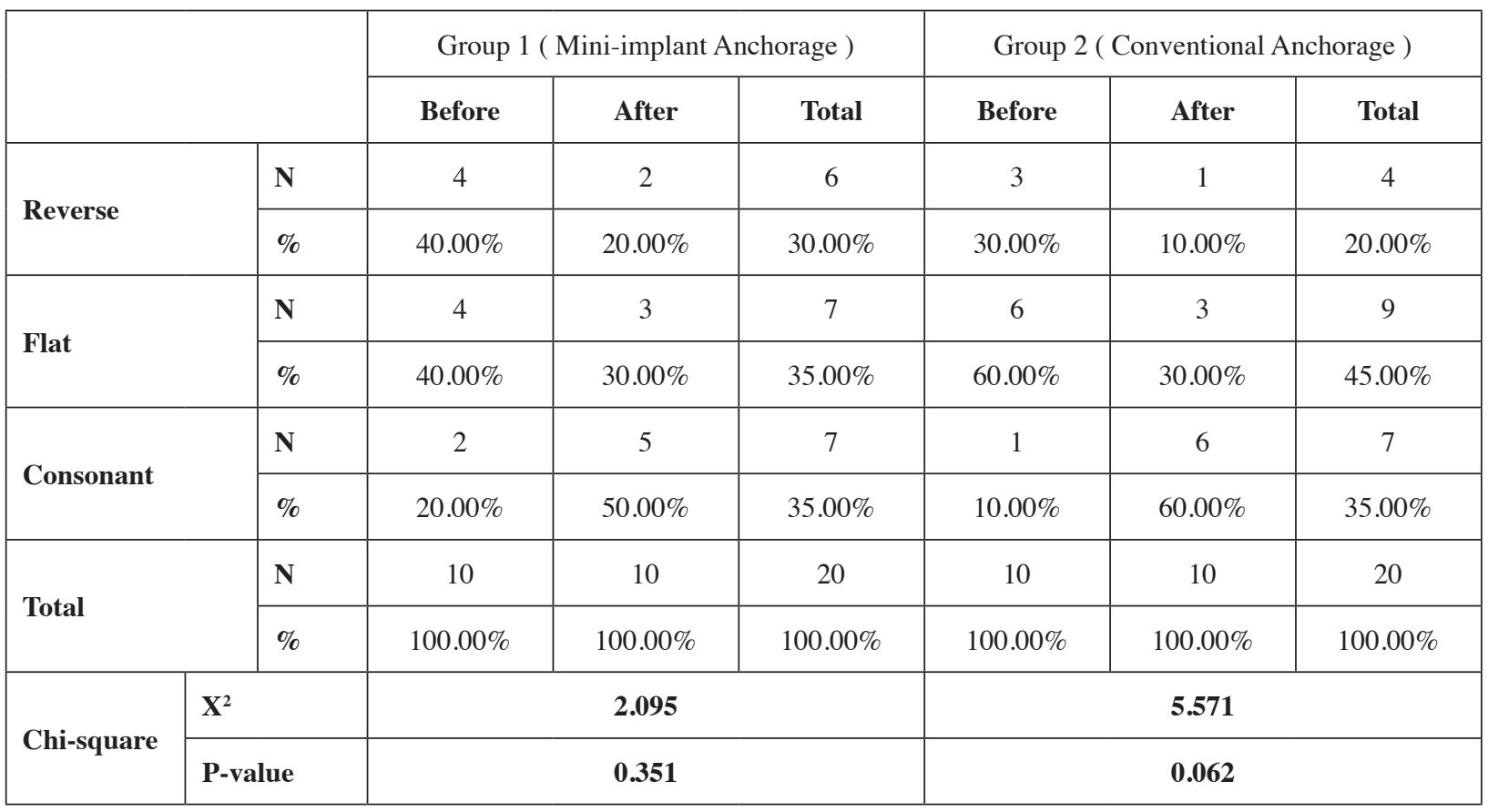

$P>0.05$ (Non significant)

\section{Cephalometric Analysis}

Antero-posteriorly, there was a significant decrease in $\mathrm{SNA}^{\circ}(-1.3 \pm 0.68, P \leq 0.001 ;-2 \pm 2.45$, $P<0.05)$ for group I and II respectively. However, there was no statistically significant differences between both groups $(P>0.05)$. For changes in $\mathrm{ANB}^{\circ}$, a significant decrease was found in group I $(-2.2 \pm 1.23, P \leq 0.001)$, whereas group II showed a statistically non-significant decrease $(-1.3 \pm 2.83$, $P=0.18)$. Although there was a statistically increase in $\mathrm{SNB}^{\circ}$ in group I $(0.9 \pm 0.99, \mathrm{P}=0.019)$, group II demonstrated a nonsignificant change $(P>0.05)$. Vertically, a significant decrease in mandibular plane angle was shown in group I $(-1.9 \pm 0.74, P<0.001)$ with a nonsignificant change in group II $(\mathrm{P}=0.081)$.

In group I and II, maxillary incisors showed significant retroclination as evident from changes in $\mathrm{U} 1-\mathrm{SN}^{\circ}(-11.6 \pm 7.66, \quad P=0.004 ;-17.5 \pm 5.04$, $P \leq 0.001)$. However, there were no significant differences between both groups $(P>0.05)$. Maxillary incisors exhibited a statistically significant intrusion in group I $(-2.3 \pm 1.06, P \leq 0.001)$ whereas group II showed a statistically significant extrusion of the upper incisors $(1.1 \pm 1.19, P \leq 0.001)$. A significant reduction in overjet $(-4.21 \pm 1.56, \quad P<0.001$; $-4.56 \pm 1.31, P<0.001)$ was noticed in both groups with no significant differences between them $(P>0.05)$. Although group I showed a significant reduction in overbite $(-1.4 \pm 1.45, P<0.05)$, group II exhibited a statistically significant deepening of the overbite $(1.81 \pm 1.55, P<0.05)$.

In the maxillary first molars movement, there were net intrusion $(\mathrm{U} 6-\mathrm{PP}=-0.80 \pm 0.92 \mathrm{~mm}$, $P \leq 0.001)$ in group $I$. The differences were highly significant when compared with group II which had extrusion (U6-PP $=0.950 \pm 0.49 \mathrm{~mm}, P \leq 0.001$ )

A significant increase in nasolabial angle was shown $(-13.6 \pm 8.09, P \leq 0.001 ; 6.6 \pm 5.93, P=0.007)$ in group I and II respectively. 


\section{Model analysis}

A significant decrease in inter-premolar arch width (IPMW) was recorded $(-2.84 \pm 1.8 ;-3.42$ $\pm 1.65)$ in group I and II respectively. Although group I showed a non-significant increase in the intermolar width (IMW: $0.63 \pm 2.79 ; \mathrm{P}>0.05$ ), group II demonstrated a statistically significant decrease in IMW $(-1.63 \pm 1.19, \mathrm{P}<0.05)$. The MB rotation of the right and left first molars in group I was -4.25 \pm 3.79 and $-3.6 \pm 3.18^{\circ}$ respectively. Significant mesialization of maxillary first molars (U6- MR, U6- LR) was recorded in group II $(-2.46+1.64$, $-1.03+1.13)$ for right maxillary molar and $(-1.82$ $+0.89,-1.93+1.45)$ for left maxillary molar $(\mathrm{P}<$ 0.05). However, mesial movements of maxillary first molars did not show statistical significance in group I ( $>>0.05)$.

\section{Smile analysis}

No significant change of upper lip length was recorded in both groups $(\mathrm{P}>0.05)$. Although both right and left buccal corridor spaces showed a reduction after treatment, this change could not reach statistical significance $(\mathrm{P}>0.05)$. Although significant intrusion of the upper incisors was recorded in group I, no significant changes could not be detected for the smile arc in both groups $(\mathrm{P}>0.05)$. While there was a high significant decrease in upper incisor display in group $\mathrm{I}(\mathrm{P}<0.001)$.

\section{Harms}

There was no looseness or mobility in minisimplants in group 1; however, inflammation of gingival tissues around miniscrews was reported in 2 cases.

\section{DISCUSSION}

Smile esthetics plays a pivotal role in orthodontic diagnosis and treatment planning as well as selfperception and social image. To minimize the effects of growth, selection was limited to only pa- tients above 18 years of age. Older age groups were not included in the current study to eliminate the effect of aging on the upper lip which could have contributed to the loss of resting muscle tone, increased flaccidity, and redundancy with age ${ }^{[1]}$.

Both treatment groups demonstrated a significant reduction in $\mathrm{SNA}^{\circ}$. This could be explained by the backward movement of A point following retraction of the upper anterior tooth ${ }^{[17-19]}$. Contradictory to the current finding, previous studies could not elaborate a significant change in the $\mathrm{SNA}^{\circ}$. This controversy might have resulted from insufficient torque control over the upper incisors during retraction ${ }^{[20-21]}$. A significant decrease in $\mathrm{ANB}^{\circ}$ was reported only in group I which could be explained by an increase in $\mathrm{SNB}^{\circ}$ following counter clockwise rotation of the mandible secondary to maxillary molar intrusion with subsequent decrease in mandibular plane angle. On the other hand, mesial movement of the posterior teeth in group II coincided with their extrusion to such an extent that they did not alter mandibular plane angle, thus nullifying the bite closing effect of posterior teeth protraction ${ }^{[22,23]}$.

A significant level of maxillary incisors intrusion was observed in group I, whereas an extrusion was found in group II. This finding was in accordance with previous studies ${ }^{[20,24,25]}$. The vertical position of mini-screw as well as the height of the crimpable hook play a defining role in directing the retraction force upward and backward. In the present study, the retraction force had two distinct components: a larger and predominantly retractive force and a smaller vertical intrusive force, causing en-masse retraction and some intrusion of the anterior teeth which resulted in a decrease in upper incisor display in group I ${ }^{[26,27]}$. On the other hand, space closure by sliding mechanics with conventional anchorage led to retroclination and extrusion of upper anterior teeth with a resultant deepening of the overbite ${ }^{[18]}$. Maxillary incisors intrusion leads to a high significant decrease in upper incisor display in group I. 
The upper first molars were intruded in group I but extruded in group II. Similar results were reported in previous studies involving en-masse retraction of maxillary anterior teeth with miniscrew as a means of anchorage ${ }^{[28,29]}$. The molar intrusion in group I could be attributed to clockwise rotation of the dental arch around the center of resistance with vertical intrusive force acting on the molars as the line of retraction force passes below the center of resistance of the entire maxillary dentition [30]. Additionally, continuation of space closure mechanics after the contact between the canine and second premolar had been established could result in force transmission to the posterior segments through the interdental contacts. This might have caused some distal movement as well as intrusion of the maxillary molars as observed in the cephalometric radiograph ${ }^{[31]}$.

Statistically significant reduction in IPMW was recorded in both groups which could be attributed to the mesial movement of posterior teeth toward the narrower anterior part of the arch [32-36]. Intermolar width in group I did not show statistical significance which supports the belief expressed by kim and Gianelly ${ }^{[1]}$ where arch constriction after extraction is not a common finding. Significant MB rotation of the first molars was recorded in group I which could help correct molar relationship due to mesio-palataly rotated molars ${ }^{[37]}$. This suggests that the use of miniscrews as a means of anchorage did not prevent correction of derotated maxillary first molars during alignment stages whereas TPA restricted their mesiobuccal rotation.

Smile arc is the relationship of the curvature of the maxillary incisal edges to the lower lip in a posed smile. Ideally, the curvature of the maxillary incisors should be parallel to the curvature of the lower lip which is referred to as consonant smile. On the other hand, flat smile arc refers to maxillary incisor arc line being flatter than the curvature of the lower lip in a posed smile ${ }^{[38]}$.
The results of the present study indicate that extraction treatment did not alter the smile arc in both groups. This disagrees with a previous study that reported smile arc flattening with subsequent less attractive smile following extraction treatment ${ }^{[39]}$. Broadness to the smile is referred to as the buccal corridor or negative space and is heavily influenced by maxillary width as well as the anteroposterior position of the maxilla relative to the lip drape. Both treatment modalities could not significantly alter the buccal corridor measurements which could be explained by the negligible effects of extraction treatment on the arch width ${ }^{[11]}$. The nasolabial angle increased significantly in both treatment groups. This may be explained by the upper lip retraction following retrusion of the maxillary incisors. Waldman studied the effect of incisal retraction on upper lip retrusion in patients with Class II malocclusion and showed that the nasolabial angle was increased by an average ratio of 1:3.8 between lip and incisor retraction ${ }^{[40]}$.

\section{REFERENCES}

1. Chetan P, Tandon P, Singh GK, Nagar A, Prasad V, Chugh VK. Dynamics of a smile in different age groups. Angle Orthod. 2013;83(1):90-96.

2. Borzabadi-Farahani A.A review of the evidence supporting the aesthetic orthodontic treatment need indices. Prog Orthod. 2012;13(3):304-313.

3. de Paula Júnior DF, Santos NC, da Silva ET, Nunes MF, Leles CR. Psychosocial impact of dental esthetics on quality of life in adolescents. Angle Orthod. 2009;79(6):1188-1193.

4. McNamara JA, Jr. Components of Class II malocclusion in children 8-10 years of age. Angle Orthod. 1981;51(3):177202.

5. Stalpers MJ, Booij JW, Bronkhorst EM, Kuijpers-Jagtman AM, Katsaros C. Extraction of maxillary first permanent molars in patients with Class II division 1 malocclusion. Am J Orthod Dentofacial Orthop. 2007;132(3):316-323.

6. Feldmann I, Bondemark L. Orthodontic anchorage: A systematic review. Angle Orthod. 2006;76(3):493-501.

7. [7] Park H-, Kim J-, Kwon T-. Treatment of a Class II deepbite with microimplant anchorage. American 
Journal of Orthodontics and Dentofacial Orthopedics. 2011;139(3):397-406.

8. Park HS, Bae SM, Kyung HM, Sung JH. Micro-implant anchorage for treatment of skeletal class I bialveolar protrusion. J Clin Orthod. 2001;35(7):417-422.

9. Dierkes JM. The beauty of the face: An orthodontic perspective. J Am Dent Assoc. 1987;Spec No:89E-95E.

10. Witzig, J.W., Spahl, R.J. The clinical management of basic maxillofacial orthopedic appliances. vol. 1. mechanics. littleton, mass. PSG Publishing; 1987: 1-13.

11. Kim E, Gianelly AA. Extraction vs nonextraction: Arch widths and smile esthetics. Angle Orthod. 2003;73(4): 354-358.

12. Paquette DE, Beattie JR, Johnston LE,Jr. A long-term comparison of nonextraction and premolar extraction edgewise therapy in "borderline" Class II patients. Am J Orthod Dentofacial Orthop. 1992;102(1):1-14.

13. Araújo LH, Zenóbio EG, Pacheco W, Cosso MG, Manzi FR, Shibli JA: Mass retraction movement of the anterior upper teeth using orthodontic mini-implants as anchorage. Oral Maxillofac Surg. 2012;16 (1):95-99.

14. Tominaga J, Tanaka M, Koga Y, Gonzales C, Kobayashi M, Yoshida N: Optimal loading conditions for controlled movement of anterior teeth in sliding mechanics. A 3D finite element study. Angle Orthod. 2009;79(6):1102- 1107.

15. Abdul Wahab R, Yamamoto Z, Sintian A, Abu Kasim N, Abidin I, Senafi S, Ariffin Z, Ariffin S: The Effects of orthodontic forces during canine retraction using selfligating brackets on gingival crevicular fluid enzyme activity, canine movement and root resorption. Sains Malaysiana. 2015;44(2):249-256.

16. Ruellas A, Pithon M, Santos R. Maxillary incisor retraction: evaluation of different mechanisms. Dental Press J. Orthod. 2013; 18(2):101-107

17. Jee JH, Ahn HW, Seo KW, et al. En-masse retraction with a preformed nickel-titanium and stainless steel archwire assembly and temporary skeletal anchorage devices without posterior bonding. Korean J Orthod. 2014;44(5):236-245.

18. Liu YH, Ding WH, Liu J, Li Q. Comparison of the differences in cephalometric parameters after active orthodontic treatment applying mini-screw implants or transpalatal arches in adult patients with bialveolar dental protrusion. J Oral Rehabil. 2009;36(9):687-695.
19. Upadhyay M, Yadav S, Nagaraj K, Patil S. Treatment effects of miniscrews for en-masse retraction of anterior teeth in bialveolar dental protrusion patients: A randomized controlled trial. Am J Orthod Dentofacial Orthop. 2008;134(1):18-29.e1.

20. Yao CC, Lai EH, Chang JZ, Chen I, Chen YJ. Comparison of treatment outcomes between skeletal anchorage and extraoral anchorage in adults with maxillary dentoalveolar protrusion. Am J Orthod Dentofacial Orthop. 2008; 134(5):615-624.

21. Park HS, Yoon DY, Park CS, Jeoung SH. Treatment effects and anchorage potential of sliding mechanics with titanium screws compared with the tweed-merrifield technique. Am J Orthod Dentofacial Orthop. 2008;133(4):593-600.

22. Cusimano C, McLaughlin RP, Zernik JH. Effects of first bicuspid extractions on facial height in high-angle cases. J Clin Orthod. 1993;27(11):594-598.

23. Staggers JA. A comparison of results of second molar and first premolar extraction treatment. Am J Orthod Dentofacial Orthop. 1990;98(5):430-436.

24. Ma J, Wang L, Zhang W, Chen W, Zhao C, Smales RJ. Comparative evaluation of micro-implant and headgear anchorage used with a pre-adjusted appliance system. Eur J Orthod. 2008;30(3):283-287.

25. Kim JS, Kim SH, Kook YA, Chung KR, Nelson G. Analysis of lingual en masse retraction combining a C-lingual retractor and a palatal plate. Angle Orthod. 2011;81(4):662-669.

26. Park HS, Kwon TG. Sliding mechanics with microscrew implant anchorage. Angle Orthod. 2004;74(5):703-710.

27. Upadhyay M, Yadav S, Nagaraj K, Uribe F, Nanda R. Miniscrews vs fixed functional appliances for treatment of young adult Class II female patients. Angle Orthod. 2012;82(2):294-303.

28. Koyama I, Iino S, Abe Y, Yamamoto T, Miyawaki S: Differences between sliding mechanics with implant anchorage and straight-pull headgear and intermaxillary elastics in adults with bimaxillary protrusion. Eur J Orthod. 2011; 33: 126-31.

29. Lee J, Miyazawa K, Tabuchi M, Kawaguchi M, Shibata M, Goto S: Midpalatal miniscrews and high-pull headgear for anteroposterior and vertical anchorage control: Cephalometric comparisons of treatment changes. Am J Orthod Dentofacial Orthop. 2013; 144: 238-50. 
30. Jung MH, Kim TW: Biomechanical considerations in treatment with miniscrew anchorage. Part I: the sagittal plane. J Clin Orthod. 2008; 42: 79-83.

31. Upadhyay M, Yadav S, Nagaraj K, Nanda R: Dentoskeletal and soft tissue effects of mini-implants in class II division 1 patients. Angle Orthod. 2009; 79:240-47.

32. Işik F, Sayinsu K, Nalbantgil D, Arun T. A comparative study of dental arch widths: Extraction and non-extraction treatment. Eur J Orthod. 2005;27(6):585-589.

33. Al Maaitah E, El Said N, Abu Alhaija ES. First premolar extraction effects on upper airway dimension in bimaxillary proclination patients. Angle Orthod. 2012;82(5):853-859.

34. Luppanapornlarp S, Johnston LE,Jr. The effects of premolar-extraction: A long-term comparison of outcomes in "clear-cut" extraction and nonextraction Class II patients. Angle Orthod. 1993;63(4):257-272.

35. Moussa R, O’Reilly MT, Close JM. Long-term stability of rapid palatal expander treatment and edgewise mechanotherapy. Am J Orthod Dentofacial Orthop. 1995; 108(5): 478-488.

36. Bishara SE, Cummins DM, Zaher AR. Treatment and posttreatment changes in patients with Class II, division 1 malocclusion after extraction and nonextraction treatment. Am J Orthod Dentofacial Orthop. 1997;111(1):18-27.

37. Maino G, Mariani L, Bozzo I, Maino G, Caprioglio A. Maxillary molar distalization with MGBM-system in Class II malocclusion. J Orthod Sci. 2013;2(3):101-108.

38. Ackerman JL, Ackerman MB, Brensinger CM, Landis JR. A morphometric analysis of the posed smile. Clin Orthod Res. 1998;1(1):2-11.

39. Sarver DM. The importance of incisor positioning in the esthetic smile: The smile arc. Am J Orthod Dentofacial Orthop. 2001;120(2):98-111.

40. Waldman BH. Change in lip contour with maxillary incisor retraction. Angle Orthod. 1982;52(2):129-134. 